\title{
Trophic transfer of micropollutants and their metabolites in an urban riverine food web
}

Aurélie Goutte $^{1 *}$, Fabrice Alliot ${ }^{1}$, Hélène Budzinski ${ }^{2}$, Caroline Simonnet-Laprade ${ }^{2}$, Raphaël Santos $^{3}$, Victor Lachaux ${ }^{1}$, Kevin Maciejewski ${ }^{2}$, Karyn Le Menach ${ }^{2}$, Pierre Labadie ${ }^{2}$

${ }^{1}$ EPHE, PSL Research University, UMR 7619 METIS, F-75005, 4 place Jussieu, Paris, France

${ }^{2}$ CNRS, EPOC, UMR 5805, F-33400 Talence, France

${ }^{3}$ HEPIA, University of Applied Sciences Western Switzerland Ecology and Engineering of Aquatic systems research group Geneva, Switzerland

* Contact: Sorbonne Université / EPHE / CNRS, UMR 7619 METIS, Case courrier 105, 4 place Jussieu, 75252 Paris Cedex 05, France, aurelie.goutte@ephe.psl.eu 


\section{Abstract:}

Trophic magnification factors (TMFs, i.e. the average change in the log-concentration of a pollutant per trophic level) have been extensively assessed for the so-called persistent organic pollutants, especially organochlorine pesticides (OCPs) and polychlorinated biphenyls (PCBs), which are biomagnified along the food web. In contrast, trophic dilution was documented for pollutants with a high metabolic transformation rate, such as phthalate plasticizers and PAHs (Polycyclic Aromatic Hydrocarbons). However, the fate of their metabolites across the food web has been rarely investigated. In this comparative study, the trophodynamics of 104 micropollutants and 25 of their metabolites were investigated in a freshwater food web from the urban Orge River, France. Trophic levels were determined using stable isotopes. Pyrethroid pesticides and their metabolites were not detected. As predicted, PCBs and OCPs biomagnified (TMF $>1$ ), while all chlorinated paraffins (CPs), PAHs and phthalates underwent a trophic dilution (TMF $<1)$. TMFs significantly decreased with metabolic transformation rate and increased with hydrophobicity. The levels of PAH or phthalate metabolites were not significantly correlated to trophic levels or underwent a trophic dilution. This study highlighted that the relative contribution of metabolite levels in TMF values calculated for both parent compound and its metabolite(s) is weak compared to TMF values of the parent compound only in a riverine food web.

Keywords: environmental analysis, freshwater ecosystem, organochlorines, chlorinated paraffins, PAH, phthalates, transformation products 


\section{Introduction}

Urban rivers are directly and continually exposed to a multitude of pollutants, as a result of poor sewage treatment, stormwater runoff from contaminated impervious surfaces, leaching from public green spaces and private gardens, atmospheric deposition and accidental discharge ${ }^{1}$. Polycyclic aromatic hydrocarbons (PAHs) and phthalate plasticizers are the most common substances causing the failure for European water bodies to achieve good chemical status ${ }^{2}$, as defined by the European Water Framework Directive (EU-WFD, 2000/60/EC). The environmental risk assessment of organic micropollutants is rendered difficult by complex processes governing their bioaccumulation, biotransformation and trophic transfer.

The Trophic Magnification Factor (TMF) is the average change in the log-concentration of a pollutant per trophic level ${ }^{3,4}$, calculated from nitrogen isotope ratios. The biomagnification potential (TMF >1) of organochlorine pesticides (OCPs) and polychlorinated biphenyls (PCBs) has been extensively described ${ }^{3}$ and has been explained by their high hydrophobicity $\left(\log K_{o w}\right)$ and low metabolic transformation rate $\left(\log k_{M}\right)^{4}$. The fate of other persistent pollutants, such as short- and medium-chain chlorinated paraffins (SCCPs and MCCPs, respectively) has been less documented in aquatic ecosystems, although they are considered as ubiquitous in freshwater ecosystems ${ }^{5}$ and raise growing concern ${ }^{6}$. Concerning micropollutants with a high metabolic transformation rate, some discrepancies have been highlighted among studies investigating their trophodynamic behavior. Laboratory experiments have shown that PAHs are transferred from prey to predator ${ }^{7}$ and undergo biomagnification along the food chain $^{8,9}$, whereas field-based studies have described trophic dilution of PAHs ${ }^{10-12}$ and phthalate diesters ${ }^{13,14}$, with predators being less contaminated than their prey in marine ecosystems.

Pollutants may indeed undergo a series of biochemical transformations in aquatic organisms at each trophic level, from bacterial communities in biofilms to macroinvertebrates (annelids, bivalves and crustaceans) $)^{15-17}$ and fish ${ }^{18-20}$, but the fate of biotransformation products across the food web has been largely neglected. Even PCBs, and especially congeners with no ortho 
chlorines, and OCPs, such as DDT (dichlorodiphenyltrichloroethane) may be metabolized at a slow rate, into hydroxylated and methylsulfonyl-PCBs and DDE (dichlorodiphenyldichloroethylene) respectively ${ }^{21}$. PAH and phthalate metabolites are mainly eliminated, but some reactive electrophilic metabolites may also covalently bind to cellular macromolecules (DNA, RNA or proteins), as evidenced by benzo(a)pyrene-derived radioactivity ${ }^{22}$, thus being potentially bioavailable to accumulate in predators. In that respect, experimental studies under laboratory conditions have evidenced that metabolites of PAH (benzo(a)pyrene, pyrene and fluoranthene) are transferred from prey to predator ${ }^{23-25}$. Hence, PAH and phthalate metabolites may have several sources: they can be generated by organisms, through biodegradation and metabolism of parent compounds, and they can be directly uptaken, through passive diffusion across membranes (e.g. gills) and sediment, particle or prey ingestion.

The present study describes the detection and levels of 104 micropollutants (16 PAHs, 7 phthalate esters, 7 pyrethroid insecticides, 30 SCCPs, 32 MCCPs, 4 organochlorine pesticides (OCPs) and 8 polychlorinated biphenyls (PCBs)) and 25 metabolites of PAHs $(\mathrm{N}=12)$, phthalates $(\mathrm{N}=9)$ and pyrethroids $(\mathrm{N}=4)$ in an urban riverine food web. The trophodynamic behavior of these micropolluants has been poorly documented in riverine ecosystems compared to coastal marine waters ${ }^{4,10-14}$. Moreover, TMFs can be applied within the context of the EU-WFD (2000/60/EC) and its daughter directive (2008/105/EC), to assess the compliance of environmental contamination levels in freshwater fish with European Environmental Quality Standards ${ }^{26}$. TMFs were calculated for 73 parent compounds and 9 metabolites and trophic levels were determined using stable nitrogen isotope ratio, as previously validated ${ }^{27}$. Biomagnification (TMF > 1) was expected for PCBs, OCPs, SCCP and MCCP, whereas trophic dilution (TMF < 1) was expected for phthalates, PAHs and to a lesser extent, their metabolites. The effect of hydrophobicity $\left(\log K_{O W}\right.$, for the log-transformed octanol-water partition coefficient) and metabolic transformation rate (log $k_{M}$ ) on TMF was tested. 


\section{Materials and methods}

\section{Sample collection}

Abiotic and biotic samples were collected from the Orge River, a minor tributary of the Seine River, France. The Orge River is dominated upstream by intensive agricultural activities in the Beauce grain-growing region and downstream by a heavily urbanized and industrialized area. Sampling was carried out during two consecutive days, the $20^{\text {th }}$ and the $21^{\text {st }}$ September 2016 , and at one study site, in order to avoid spatial and temporal variation in contaminants and stable isotopes. The sampling station, Viry-Châtillon [48 $\left.40^{\prime} 23^{\prime \prime} \mathrm{N} ; 2^{\circ} 21^{\prime} 30^{\prime \prime} \mathrm{E}\right]$ is located ca. $3 \mathrm{~km}$ upstream of the confluence with the Seine River (Supporting Information, Figure S1), in a dense urban area. High PAHs and phthalate ester contaminations have been previously reported at this station in surface sediment, water and in European perch Perca fluviatilis, chub Squalius cephalus, and common roach Rutilus rutilus $^{28,29}$.

A total of 45 pooled samples were collected, which is considered as an appropriate sample size for TMF estimation ${ }^{3}$. Primary producers include epilithic biofilm $(\mathrm{N}=2)$, leaf-litter $(\mathrm{N}=2)$, and macrophyte Hydrocotyle ranunculoides $(\mathrm{N}=2)$. Biofilm material was scraped from randomly selected submerged rocks. Five genera of macro-invertebrates were sampled using a $0.05 \mathrm{~m}^{2}$ Surber-type sampling device (mesh $300 \mu \mathrm{m})$ : Gammarus sp. $(\mathrm{N}=3$ pools $)$, Lymnaea $s p .(\mathrm{N}=3$ pools), Corbicula sp. $(\mathrm{N}=1$ pools $)$, Notonecta $s p .(\mathrm{N}=1$ pool $)$ and Glossophoniidae sp. $(\mathrm{N}=1$ pool). Whole organisms were analysed. Forty-six fish belonging to eight species were caught using an electrofishing device (Martin pecheur®, DREAM Electronique, $240 \mathrm{~W}$ ). Stunned fish were collected with a dip-net and were lethally anesthetized with tricaine methane sulphonate (MS222, 1g. $\mathrm{L}^{-1}$ in river water). Fish sampling authorization was delivered by local administration authorities (Departmental Direction of Territories), in full accordance with the French Environment Policy (including water policy) and European standards (EN14011). Fish were pooled by species (whole organism) and size class when necessary: common barbel Barbus barbus $(\mathrm{N}=1$, total length $(\mathrm{TL})=$ $14 \mathrm{~cm}$, weight $(\mathrm{W})=25 \mathrm{~g})$, common roach $(\mathrm{N}=4$ pools of 1 or 2 individuals, TL $($ mean $+\mathrm{SD})=10$ 
$\pm 2 \mathrm{~cm}, \mathrm{~W}=12 \pm 6 \mathrm{~g})$, European perch $(\mathrm{N}=4$ pools of 2 or 3 individuals, $\mathrm{TL}=7 \pm 1 \mathrm{~cm}, \mathrm{~W}=4 \pm$ $1 \mathrm{~g}$ ), gudgeon Gobio gobio $(\mathrm{N}=4$ pools of 1 or 2 individuals, $\mathrm{TL}=10 \pm 1 \mathrm{~cm}, \mathrm{~W}=11 \pm 3 \mathrm{~g})$, tench Tinca tinca $(\mathrm{N}=4$ individuals, $\mathrm{TL}=12 \pm 1 \mathrm{~cm}, \mathrm{~W}=25 \pm 8 \mathrm{~g})$, bullhead Cottus gobio $(\mathrm{N}=4$ pools of 1 or 2 individuals, $\mathrm{TL}=11 \pm 1 \mathrm{~cm}, \mathrm{~W}=11 \pm 3 \mathrm{~g})$, pumpkinseed Lepomis gibbosus $(\mathrm{N}=5$ pools of 1 to 3 individuals, $\mathrm{TL}=7 \pm 2 \mathrm{~cm}, \mathrm{~W}=8 \pm 5 \mathrm{~g})$ and black bullhead Ameiurus melas $(\mathrm{N}=4$ individuals, $\mathrm{TL}=12 \pm 2 \mathrm{~cm}, \mathrm{~W}=22 \pm 9 \mathrm{~g}$ ). Detailed information on the samples is provided in Table S1 (SI). The samples were stored at $-20^{\circ} \mathrm{C}$ in glassware and polycarbonate tubes.

\section{Chemicals, reagents and materials}

Acetone, n-hexane, dichloromethane and ethyl acetate were purchased from Merck (Fontenay-sousBois, France); ammonium acetate, phosphoric acid and isopropanol from Sigma-Aldrich (Germany); acetonitrile (ACN) and methanol (MetOH) from VWR Chemicals (Fontenay-sous-Bois, France); formic acid from Carlo Erba Reagents (Val-de-Reuil, France). Helium and nitrogen (99.999\%) were supplied by Air Liquide (Paris, France). All solvents were of gas and liquid chromatography quality and free from phthalate residues.

The analyses included 16 PAHs (naphthalene: Nap, acenaphthylene: Acy, acenaphthene: Ace, fluorine: F, phenanthrene: Phe, anthracene: Ant, fluoranthene: Fl, pyrene: Pyr, benzo(a)anthracene: BaA, chrysene: $\mathrm{Chr}$, benzo(b)fluoranthene: $\mathrm{BbF}$, benzo(k)fluoranthene: BkF, benzo(a)pyrene: $\quad \mathrm{BaP}, \quad$ indeno(1,2,3-cd)pyrene, dibenzo(a,h)anthracene: DahA, and benzo(g,h,i)perylene: BghiP), 7 phthalate diesters (dimethyl phthalate: DMP, diethyl phthalate: DEP, n-butyl benzyl phthalate: BBP, di-n-butyl phthalate: DnBP, di-iso-decyl phthalate: DiBP, di2-ethylhexyl phthalate: DEHP and di-n-octyl phthalate: DnOP), 7 pyrethroid pesticides (bifenthrin, permethrin, phenothrin, cyfluthrin, cypermethrin, fenvarelate and deltamethrin), 4 OCPs (pentachlorobenzene: PeCB, hexachlorobenzene: HCB, lindane: $\gamma$-HCB and dichlorodiphenyldichloroethylene: p,p'-DDE), 8 PCBs (CB-28, -50, -52, -101, -118, -153, -138, and -180), 30 SCCPs, 32 MCCPs, 12 PAH metabolites (1-hydroxynaphthalene: 1-OH-Nap, 2- 
hydroxynaphthalene: 2-OH-Nap, 2-hydroxyfluorene: 2-OH-Flu, 3-hydroxyfluorene: 3-OH-Flu, 9hydroxyfluorene: 9-OH-Flu, 1-hydroxyphenanthrene: 1-OH-Phe, 3-hydroxyphenanthrene: 3-OHPhe, 4-hydroxyphenanthrene: 4-OH-Phe, 1-hydroxypyrene: 1-OH-Pyr, 6-hydroxychrysene: 6-OHChr and 3-hydroxybenzo(a)pyrene: 3-OH-BaP), 7 phthalate monoesters (mono-methyl phthalate: MMP, mono-ethyl phthalate : MEP, mono-iso-butyl phthalate: MiBP, mono-n-butyl phthalate: MnBP, mono-benzyl phthalate: MBzP, mono-n-octyl phthalate: MnOP and mono-2-ethylhexyl phthalate: MEHP), two oxidized by-products (mono-2-ethyl-5-oxohexyl phthalate: MEOHP and mono-2-ethyl-5-hydroxyhexyl phthalate: MEHHP) and 4 pyrethroid metabolites (3-(2,2dichlorovinyl)-2,2-dimethyl-1-cyclopropane: cis-DCCA and trans-DCCA, 4-fluoro-3phenoxybenzoic acid: 4-FPBA, and 3-phenoxybenzoic acid: 3-PBA).

\section{Chemical analyses}

Samples were freeze-dried for $48 \mathrm{~h}$ and ground into a fine and homogeneous powder using a micro ball mill $(25 \mathrm{~Hz})$. Firstly, $500 \mathrm{mg}$ of samples were spiked with a mixture of internal standards for analyses of PAHs, phthalates, pyrethroids and OCPs (phenanthrene- $\mathrm{d}_{10}$, pyrene- $\mathrm{d}_{10}$, benzo(a)anthracene-d $\mathrm{d}_{12}$ (Cluzeau Info Labo, Sainte-Foy-la-Grande, France), DEP- $\mathrm{d}_{4}$ and DEHP- $\mathrm{d}_{4}$ (LGC standards, Molsheim, France), ${ }^{13} \mathrm{C}$ Cis permethrin and lindane- $\mathrm{d}_{6}$ (BCP instruments, Oullins, France)). Samples were processed according to validated methods ${ }^{30}$, through Accelerated Solvent Extraction (ASE 350, Thermo Fisher Scientific), using different solvents (hexane: DCM, 1:1, and hexane: acetone, 1:1), purifications using Florisil cartridges (Supelco 1g/6mL, Sigma-Aldrich, St Quentin Fallavier, France) and PAHs, phthalate diesters, pyrethroid pesticides and OCPs were analyzed using an Agilent 7890 A gas chromatograph (GC) coupled to a 7000 B triple quadrupole mass spectrometer system (MS/MS) (Agilent Technologies, Les Ulis, France).

Secondly, PCBs were analyzed as previously described ${ }^{31}$. Briefly, approximately 200-500 mg of each sample was spiked with internal standards (i.e., CB-30, -103, -155 and -198, $1.5 \mathrm{ng}$ each) and analytes were extracted via microwave-assisted extraction with dichloromethane (DCM). 
The so-obtained organic extract was filtered, concentrated, and cleaned-up using $\mathrm{H}_{2} \mathrm{SO}_{4}$ impregnated silica gel columns. Final extracts were spiked with the injection standard octachloronaphthalene (1 ng) prior to analysis with a $6890 \mathrm{~N}$ gas chromatograph (Agilent Technologies, Massy, France) coupled to a ${ }^{63} \mathrm{Ni}$ electron-capture detector (ECD). Thirdly, SCCPs and MCCPs were analyzed using validated methods ${ }^{5}$. Approximately $200-500 \mathrm{mg}$ of each sample was spiked with $1 \mathrm{ng}$ of ${ }^{13} \mathrm{C}_{10}-\mathrm{C}_{10} \mathrm{H}_{16} \mathrm{Cl}_{6}$ (used as surrogate) and extracted using microwave-assisted extraction with DCM. Extract purification was performed using bilayer columns $\left(\mathrm{H}_{2} \mathrm{SO}_{4}\right.$ impregnated silica gel and activated silica gel). Extracts were then concentrated and spiked with the injection standard $\left({ }^{13} \mathrm{C}_{10}\right.$-syn-Dechlorane Plus). Analysis was performed by GC-MS using an Agilent 7890B GC system coupled to an Agilent 7200 Q-TOF analyzer.

At last, PAH, phthalate and pyrethroid metabolite analyses were conducted according to recently validated methods ${ }^{30}$. Samples $(500 \mathrm{mg})$ were homogenized in ammonium acetate $(2 \mathrm{~mL}$, $1 \mathrm{M}, \mathrm{pH}$ 6.5), using a vortex (15s) and ultrasound $(10 \mathrm{~min}) . \beta$-glucuronidase $(10 \mu \mathrm{L}$, from Escherichia coli K12, Sigma-Aldrich, Germany) was added to deconjugate metabolites (90 min, 37 $\left.{ }^{\circ} \mathrm{C}, 170 \mathrm{rpm}\right)$. Samples were spiked with internal standards $\left(2-\mathrm{OH}-\mathrm{Nap}{ }^{13} \mathrm{C}_{6}, 1-\mathrm{OH}-\mathrm{Pyr}{ }^{13} \mathrm{C}_{6}, 9-\mathrm{OH}-\right.$ Flu ${ }^{13} \mathrm{C}_{6}, 1-\mathrm{OH}-\mathrm{Phe}^{13} \mathrm{C}_{6}$ and 6-OH-Chr ${ }^{13} \mathrm{C}_{6}, \mathrm{MnBP}-{ }^{13} \mathrm{C}_{12}, \mathrm{MEHP}-{ }^{13} \mathrm{C}_{12}$ and MiNP- $\left.{ }^{13} \mathrm{C}_{12}, \mathrm{OH}-\mathrm{PAH}\right)$ and with 4-methylumbelliferyl- $\beta$-D-glucuronide (10 $\mu \mathrm{L}$ at $57.5 \mathrm{ng} . \mu \mathrm{L}-1, \mathrm{LGC}$ standards, Molsheim, France), as a control of the deconjugation reaction. Samples were processed using Oasis HLB cartridges (6 mL/200 mg, Waters, Guyancourt, France). All extracts were stored at $-18^{\circ} \mathrm{C}$ until use. Metabolites were quantified using an Agilent 1200 liquid chromatograph (LC) interfaced to a 6410B triple quadrupole mass spectrometer system (MS/MS).

\section{Quality Assurance and Quality Control}

Procedural blanks were analyzed with each batch of samples. Results were blank-corrected when applicable. The average recovery rates of analytes from spiked subsamples of leaf-litter $(\mathrm{N}=$ 3), biofilm $(\mathrm{N}=3)$, Gammarus sp. $(\mathrm{N}=3)$, Lymnaea sp. $(\mathrm{N}=3)$, gudgeon $(\mathrm{N}=3)$ and blank $(\mathrm{N}=1)$, 
were $109 \pm 15 \%$ (phthalate esters), $91 \pm 15 \%$ (phthalate metabolites), $122 \pm 10 \%$ (PAHs), $67 \pm 26$ $\%$ (PAH metabolites), $118 \pm 11 \%$ (pyrethroids), $99 \pm 11 \%$ (pyrethroid metabolites) and $105 \pm 7 \%$ (OCPs). The average recovery rates from spiked fish tissues were $98 \pm 15 \%$ (PCBs), $80 \pm 15 \%$ (SCCPs) and $120 \pm 20 \%$ (MCCPs) (n=4). For most analytes, the limits of detection (LODs) and quantification (LOQs) were determined based on the signal to noise ratio or on the variability of blanks; for CPs, however, LODs were determined based on the variability of the concentration determined experimentally in fish tissues fortified at low level ${ }^{5}$. LOQ are detailed for each compound in Table S2.

\section{Lipid content}

Briefly, aliquots $(0.1-0.5 \mathrm{~g})$ of each homogenized dried tissue sample were extracted by ASE as previously described ${ }^{32}$. Extracts were dried by evaporation and residues were weighed to the nearest $0.1 \mathrm{mg}$ to calculate tissue lipid content (in $\% \mathrm{dw}$ ). The so-obtained defatted tissues were dried at room temperature in a fume cupboard and stored in amber flasks until $\mathrm{C} / \mathrm{N}$ stable isotope analysis. Levels of pollutants and metabolites were expressed in $\mu \mathrm{g}$ or $\mathrm{ng} \cdot \mathrm{g}^{-1}$ lipid weight (lw).

Stable Isotope Analysis and Trophic Level Determination

Stable carbon and nitrogen isotope ratio $\left(\delta^{13} \mathrm{C}, \delta^{15} \mathrm{~N}\right)$ was determined in triplicate for each sample after lipid extraction by ASE, using a Thermo Finnigan Delta V EA-IRMS (Elemental Analyzer - Isotope Ratio Mass Spectrometry) with a Conflo IV interface ${ }^{32}$. Nitrogen isotope compositions were expressed as per mil (\%o) in the $\delta$ notation relative to atmospheric $\mathrm{N}_{2}$. The reproducibility was less than 5\%. Trueness was determined using reference materials, i.e. IAEA-N2 $\left(\delta^{15} \mathrm{~N}=20.3 \% \pm 0.2 \%\right.$ o $)$ and USG-24 $\left(\delta^{13} \mathrm{C}=-16.1 \pm 0.2 \%\right)$. Food web structure using the combination of $\mathrm{C}$ and $\mathrm{N}$ stable isotopes had been previously validated for this data $\operatorname{set}^{33}$. 
The trophic level of each sample was calculated according to the following formula: Trophic Level consumer $=2+\left(\delta^{15} \mathrm{~N}_{\text {consumer }}-\delta^{15} \mathrm{~N}_{\text {base }}\right) / 3.4$. The constant 2 corresponds to the estimated trophic position of the organism at the base of the food web, which in the present case is Corbicula sp., a primary consumer ${ }^{3,27} . \delta^{15} \mathrm{~N}_{\text {consumer }}$ and $\delta^{15} \mathrm{~N}_{\text {base }}$ are the $\delta^{15} \mathrm{~N}$ of consumer and baseline organisms. $3.4 \%$ is the mean trophic fractionation of $\delta^{15} \mathrm{~N}$ across two successive trophic levels ${ }^{27}$.

Stable isotope compositions and trophic level estimations of each sample are detailed in Table S1 (SI), as well as lipid content, humidity content and value of each pollutant family. Because lipid extraction may affect stable isotope compositions ${ }^{34}$, we also conducted isotope analyses on untreated samples $(\mathrm{N}=39)$ and found an only very small isotope shift in $\delta^{15} \mathrm{~N}$ values (mean $\pm \mathrm{SD}$ : $0.29 \pm 0.52)$, which was consistent with previous study on aquatic organisms ${ }^{35}$.

\section{Statistical analyses}

TMFs were calculated only for chemicals with a detection frequency higher than $40 \%$ using slope coefficients of significant linear regressions between concentration of the chemical in the whole organism (log-transformed, $n g . \mathrm{g}^{-1} \mathrm{lw}$ ) and trophic level. Tobit models were used to estimate linear regressions for left-censored dependent variables (levels of pollutant < LOD), using the function tobit of the AER R-package ${ }^{36}$. Log $K_{\text {OW }}$ values were obtained using the free online Molinspiration Cheminformatics web services (http://www.molinspiration.com/) and metabolic biotransformation rate $\left(\log k_{M}\right)$ values were obtained with the BCFBAF module in EPIWEB $4.1^{37}$. Variations in TMF values were assessed with $\log K_{\mathrm{OW}}\left(\right.$ or $\log k_{\mathrm{M}}$ ) as fixed effects and group of pollutants as random effect, using linear mixed models (LMMs) via nlme R-package ${ }^{38}$. Log $K_{O W}$ and $\log k_{M}$ are provided in Table S2 (SI). As $\log K_{\mathrm{OW}}$ and $\log k_{\mathrm{M}}$ were highly correlated (LMM: $\left.F_{1,60}=64.433, p<0.001\right)$, they were not both included as fixed effect in LMM analyses. 


\section{Results and discussion}

\section{Trophic transfer of organochlorines}

Detection frequencies and levels of micropollutants are described in SI. As previously reported in other food $\mathrm{web}^{3}$, TMFs were higher than 1 (i.e. indicative of biomagnification) in this freshwater food web for OCP and PCB congeners (Table S2, Figure S2 A,B).

SCCP or MCCP concentrations declined with trophic level (TMF $<1$, Figure 2 A,B, Table S2), suggesting a trophic dilution of these compounds in the Orge river. Previous studies reported either biomagnification in freshwater and coastal habitats for some homologue groups ${ }^{39,40}$, or trophic dilution in other cases ${ }^{41}$. Differences in food web characteristics and species-differences in the ability to metabolize these chemicals might be relevant factors explaining such discrepancies ${ }^{3}$.

\section{Trophic transfer of PAH, phthalates}

PAH and phthalates underwent a pronounced trophic dilution (Figure 1A, B, Table S2), thereby confirming previous observations obtained in marine ecosystems with TMF or Food-Web Magnification Factor (FWMF) lower than $1^{10-14}$. Trophic dilution of PAHs and phthalates is attributed to the ability of aquatic species to biotransform these chemicals with fish having a higher biotransformation efficiency (liver in vertebrate species) than macroinvertebrates (hepatopancreas of crustaceans, digestive gland of molluscs $)^{17,42}$. More specifically, the efficiency to biotransform phthalates or PAHs increased in the following order: algae $<$ cnidarians $<$ molluscs $<$ crustaceans $<$ $\operatorname{fish}^{43,44}$.

$T M F$, hydrophobicity and metabolic rate 
In a literature meta-analysis of 69 articles $^{4}$, hydrophobicity and metabolic biotransformation rate were shown to be key drivers of TMFs for 481 chemicals belonging to 10 classes of organic compounds. In the present study of an urban river food web, we tested whether TMFs calculated for 73 compounds belonging to 6 pollutant groups were linked to $\log K_{\mathrm{OW}}$ and $\log k_{\mathrm{M}}$. It is important to emphasize that TMFs were estimated in the same food web, during a short period of time (2 days of sampling) and at a restricted sampled site $(<500 \mathrm{~m}$ of a river transect $)$, thus reducing variability in environmental (temperature, dissolved organic carbon concentrations, water pollution) and ecological conditions. TMF (log-transformed) significantly increased with hydrophobicity, when considering group of pollutants as a random effect (Figure 3A, LMM: $\mathrm{F}_{1,60}=5.507, \mathrm{p}=0.022$ ), as previously found in the meta-analysis ${ }^{4}$.

In the current study, metabolic biotransformation rates (log-transformed) were negatively correlated to log TMF, when considering group of pollutants as a random effect (Figure 3B, LMM: $F_{1,60}=7.818, p=0.007$ ), with PCBs and OCPs being the compounds with the highest TMFs and the lowest metabolic biotransformation rates, followed by SCCPs and MCCPs, then by PAHs and phthalates having the lowest TMF values and the highest $\log k_{\mathrm{M}}$. Such results confirm that trophic magnification and dilution are driven by metabolic rate ${ }^{4}$.

Other factors play crucial roles in bioaccumulation and biomagnification processes, such as food consumption, respiratory intake, respiratory loss, fecal elimination, urinary excretion and metabolism ${ }^{45}$. Here, the effect of the octanol-air partition coefficient $\left(\mathrm{K}_{\mathrm{OA}}\right)$ of pollutants was not tested on TMF values, since no air-breathing animal was sampled and respiratory elimination to air was considered as negligible. Elimination of pollutants during insect metamorphosis may further accelerate the trophic dilution of PAHs and phthalates ${ }^{46}$. At last, individual traits, such as age and sex may also explain the bioaccumulation of persistent organic pollutants in terrestrial ${ }^{47}$ and aquatic $^{48}$ vertebrates, but not levels of PAH, phthalates and their metabolites in fish ${ }^{49,50}$. 
A novel aspect of this study is its consideration of the fate of metabolites across the food web, as this has been previously recommended ${ }^{45}$ but poorly-conducted ${ }^{14,51}$. The levels of 1 hydroxypyrene significantly declined with trophic level in the Orge river (Figure 1C), whereas the tobit regressions were not significant for sum of hydroxyphenanthrenes and 6-hydroxychrysene. Among phthalate metabolites, only MEHHP and MEOHP significantly declined with trophic level (Figure 1C, D, Table S2). TMF values were higher for phthalate metabolites compared to their corresponding parent compounds (Table S2). Metabolites can be directly incorporated from the environment (respiration through gills, ingestion of sediments and suspended matter), transferred from prey to predators (food consumption) and generated through biodegradation or metabolism of parent compounds. The excretion rates of metabolites could be slower than the transformation and elimination rates of parent compounds ${ }^{42}$, thus explaining the lower trophic dilution of metabolites compared to parent compounds. The fate of phthalate metabolites was investigated in a marine ecosystem ${ }^{14}$ and trophic dilution was described for both phthalate esters and monoalkyl phthalate esters. Since concentrations were given on a wet weight basis and TMF values were not calculated in this study ${ }^{14}$, their results are therefore difficult to compare with our study. In our data set, when calculating TMF values of phthalate metabolites on a wet weight (ww) basis, completely different results were obtained: phthalate metabolites in $\mathrm{ng} / \mathrm{g}$ ww underwent a strong biomagnification across the riverine food web, with TMFs ranging from 2.26 to 3.95. Even if phthalate metabolites are more water-soluble than their parent compounds, we calculated TMF values from concentrations on a $1 \mathrm{w}$ basis, in order to compare TMF among pollutants and with other studies ${ }^{4,10,13}$.

Lastly, we showed that the combined levels of parent compound and its metabolite decreased with increasing trophic level (Figure 1E, F). TMF values were calculated for DIBP and MiBP (estimate and 95\% confidence interval: $0.40[0.33 ; 0.48]$, Wald $\chi^{2}=24.15, \mathrm{p}<0.001$ ), DnBP and MnBP (0.40 [0.32;0.49], DEHP, MEHP, MEOHP and MEHHP $\left(0.15\right.$ [0.10;0.23], Wald $\chi^{2}=$ $22.88, \mathrm{p}<0.001)$, sum of hydroxyphenanthrene and phenanthrene $\left(0.13[0.10 ; 0.17]\right.$, Wald $\chi^{2}=$ 68.21, $\mathrm{p}<0.001), 1$-hydroxypyrene and pyrene $\left(0.06[0.06 ; 0.07]\right.$, Wald $\left.\chi^{2}=131.1, \mathrm{p}<0.001\right)$, 
chrysene and 6-hydroxychrysene $\left(0.12[0.07 ; 0.18]\right.$, Wald $\left.\chi^{2}=24.28, \mathrm{p}<0.001\right)$ and were similar than the TMF values of the parent compound only (Table S2). The relative contribution of metabolite levels in TMF values may therefore be considered as negligible for PAHs and phthalates in this riverine food web. 


\section{References}

(1) Schwarzenbach, R. P.; Escher, B. I.; Fenner, K.; Hofstetter, T. B.; Johnson, C. A.; Von Gunten,

U.; Wehrli, B. The challenge of micropollutants in aquatic systems. Science 2016, 313(5790), 10721077

(2) Malaj, E.; Peter, C.; Grote, M.; Kühne, R.; Mondy, C. P.; Usseglio-Polatera, P.; Brack, W.;

Schäfer, R. B. Organic chemicals jeopardize the health of freshwater ecosystems on the continental scale. Proc. Natl. Acad. Sci. U.S.A. 2014, 111(26), 9549-9554

(3) Borgå, K.; Kidd, K. A.; Muir, D. C.; Berglund, O.; Conder, J. M.; Gobas, F. A.; Powell, D. E. Trophic magnification factors: considerations of ecology, ecosystems, and study design. Integr. Environ. Assess. Manag. 2012, 8(1), 64-84.

(4) Walters, D. M.; Jardine, T. D.; Cade, B. S.; Kidd, K. A.; Muir, D. C. G.; Leipzig-Scott, P. Trophic magnification of organic chemicals: A global synthesis. Environ. Sci. Technol. 2016, 50(9), 4650-4658.

(5) Labadie, P.; Blasi C.; Le Menach, K.; Geneste, E.; Babut, M.; Perceval, O.; Budzinski, H. Evidence for the widespread occurrence of Short- and Medium-Chain Chlorinated Paraffins in fish collected from the Rhône River basin (France). Chemosphere 2019, 223, 232-239.

(6) van Mourik, L. M.; Gaus, C.; Leonards, P. E. G.; de Boer, J. Chlorinated paraffins in the environment: A review on their production, fate, levels and trends between 2010 and 2015. Chemosphere 2016, 155, 415-428.

(7) Filipowicz, A. B.; Weinstein, J. E.; Sanger, D. M. Dietary transfer of fluoranthene from an estuarine oligochaete (Monopylephorus rubroniveus) to grass shrimp (Palaemonetes pugio): influence of piperonyl butoxide. Mar. Environ. Res. 2007, 63(2), 132-145. 
(8) Froehner, S.; Maceno, M.; Machado, K. S. Predicting bioaccumulation of PAHs in the trophic chain in the estuary region of Paranagua, Brazil. Environ. Monit. Assess. 2011, 174(1-4), 135-145.

(9) Richter, S.; Nagel, R. Bioconcentration, biomagnification and metabolism of 14C-terbutryn and 14C-benzo [a] pyrene in Gammarus fossarum and Asellus aquaticus. Chemosphere, 2007, 66(4), 603-610.

(10) Wan, Y.; Jin, X.; Hu, J.; Jin, F. Trophic dilution of polycyclic aromatic hydrocarbons (PAHs) in a marine food web from Bohai Bay, North China. Environ. Sci. Technol. 2007, 41(9), 3109-3114.

(11) Nfon, E.; Cousins, I. T.; Broman, D. Biomagnification of organic pollutants in benthic and pelagic marine food chains from the Baltic Sea. Sci. Total Environ. 2008, 397(1-3), 190-204.

(12) Takeuchi, I.; Miyoshi, N.; Mizukawa, K.; Takada, H.; Ikemoto, T.; Omori, K.; Tsuchiya, K. Biomagnification profiles of polycyclic aromatic hydrocarbons, alkylphenols and polychlorinated biphenyls in Tokyo Bay elucidated by $\delta 13 \mathrm{C}$ and $\delta 15 \mathrm{~N}$ isotope ratios as guides to trophic web structure. Marine Poll. Bull. 2009, 58, 663-671

(13) Mackintosh, C. E.; Maldonado, J.; Hongwu, J.; Hoover, N.; Chong, A.; Ikonomou, M. G.; Gobas, F. Distribution of phthalate esters in a marine aquatic food web: comparison to polychlorinated biphenyls. Environ. Sci. Technol. 2004, 38, 2011-2020.

(14) Hu, X.; Gu, Y.; Huang, W.; Yin, D. Phthalate monoesters as markers of phthalate contamination in wild marine organisms. Environ. Pollut. 2016, 218, 410-418.

(15) Varanasi, U.; Reichert, W.L.; Stein, J. E.; Brown, D. W.; Sanborn, H.R. Bioavailability and biotransformation of aromatic hydrocarbons in benthic organisms exposed to sediment from an urban estuary. Environ. Sci. Technol. 1985, 19, 836-841. 
(16) Livingstone D. R. The fate of organic xenobiotics in aquatic ecosystems: quantitative and qualitative differences in biotransformation by invertebrates and fish. Comp. Biochem. Physiol. A Mol. Integr. Physiol. 1998, 120, 43 -49

(17) Rust, A. J.; Burgess, R. M.; Brownawell, B. J.; McElroy, A. E. Relationship between metabolism and bioaccumulation of benzo $[\alpha]$ pyrene in benthic invertebrates. Environ. Toxicol. Chem. 2004, 23(11), 2587-2593.

(18) Lee, R. F.; Sauerheber, R.; Dobbs, G. H. Uptake, metabolism and discharge of polycyclic aromatic hydrocarbons by marine fish. Mar. Biol. 1972, 17(3), 201-208

(19) Barron, M. G.; Albro, P. W.; Haytons, W. L. Biotransformation of di(2-ethylhexyl)phthalate by rainbow trout. Environ. Toxicol. Chem. 1995, 14(5), 873-876.

(20) Valton, A. S.; Serre-Dargnat, C.; Blanchard, M.; Alliot, F.; Chevreuil, M.; Teil, M. J. Determination of phthalates and their by-products in tissues of roach (Rutilus rutilus) from the Orge river (France). Environ. Sci. Pollut. Res. Int. 2014, 21(22), 12723-12730.

(21) Grimm, F. A.; Hu, D.; Kania-Korwel, I.; Lehmler, H. J.; Ludewig, G.; Hornbuckle, K. C., Duffel, M. W.; Bergman, A.; Robertson, L. W. Metabolism and metabolites of polychlorinated biphenyls. Crit. Rev. Toxicol. 2015, 45(3), 245-272.

(22) Reichert, W. L.; Le Eberhart, B. T.; Varanasi, U. Exposure of two species of deposit-feeding amphipods to sediment-associated $[3 \mathrm{H}]$ benzo [a] pyrene: uptake, metabolism and covalent binding to tissue macromolecules. Aquat. Toxicol. 1985, 6(1), 45-56.

(23) McElroy, A. E.; Sisson, J. D. Trophic transfer of benzo [a] pyrene metabolites between benthic marine organisms. Mar. Environ. Res. 1989, 28(1-4), 265-269. 
(24) Navarro, V. C.; Leppänen, M. T.; Honkanen, J. O.; Kukkonen, J. V. K. Trophic transfer of pyrene metabolites and nonextractable fraction from Oligochaete (Lumbriculus variegatus) to juvenile brown trout (Salmo trutta). Chemosphere 2012, 88, 55e61.

(25) Navarro, V. C.; Leppänen, M. T.; Kukkonen, J. V. K.; Olmos, S. G. Trophic transfer of pyrene metabolites between aquatic invertebrates. Environ. Pollut. 2013, 173, 61-67.

(26) Kidd, K. A.; Burkhard, L.P.; Babut, M.; Muir, D. C. Practical Advice for Selecting or Determining Trophic Magnification Factors for Application under the European Union Water Framework Directive. Integr. Environ. Assess. Manag. 2018, 15(2), 266-277.

(27) Post, D.M. Using stable isotopes to estimate trophic position: models, methods, and assumptions. Ecology 2002, 83, 703-718.

(28) Teil, M. J.; Tlili, K.; Blanchard, M.; Chevreuil, M.; Alliot, F.; Labadie, P. Occurrence of polybrominated diphenyl ethers, polychlorinated biphenyls, and phthalates in freshwater fish from the Orge River (Ile-de France). Arch. Environ. Contam. Toxicol. 2012, 63(1), 101-113.

(29) Teil, M. J.; Tlili, K.; Blanchard, M.; Labadie, P.; Alliot, F.; Chevreuil, M. Polychlorinated biphenyls, polybrominated diphenyl ethers, and phthalates in roach from the Seine River basin (France): impact of densely urbanized areas. Arch. Environ. Contam. Toxicol. 2014, 66(1), 41-57.

(30) Molbert, N.; Alliot, F.; Santos, R.; Chevreuil, M.; Mouchel, J.-M.; Goutte, A. Multi-residue methods for the determination of organic micropollutants and their metabolites in fish tissues from the Marne hydrographic network (France). Environ. Toxicol. Chem. 2019, 38, 1866-1878.

(31) Bodin, N.; Tapie, N.; Le Ménach, K.; Chassot, E.; Elie, P.; Rochard, E.; Budzisnki, H. PCB Contamination in Fish Community from the Gironde Estuary (France): Blast from the Past. Chemosphere 2014, 98, 66-72. 
(32) Bodin, N. ; Budzinski, H. ; Le Menach, K. ; Tapie, N. ASE extraction method for simultaneous carbon and nitrogen stable isotope analysis in soft tissues of aquatic organisms. Anal. Chim. Acta 2009, 643, 54-60.

(33) Simonnet-Laprade, C.; Budzinski, H.; Maciejewski, K.; Le Menach, K.; Santos, R.; Alliot, F.; Goutte, A.; Labadie, P. Biomagnification of perfluoroalkyl acids (PFAAs) in the food web of an urban river: assessment of the trophic transfer of targeted and unknown precursors and implications. Environ. Sci. Proc. Imp. 2019, 21(11), 1864-1874.

(34) Sotiropoulos, M. A.; Tonn, W. M.; Wassenaar, L. I. Effects of lipid extraction on stable carbon and nitrogen isotope analyses of fish tissues: potential consequences for food web studies. Ecology of Freshwater Fish 2004, 13(3), 155-160.

(35) Ingram, T.; Matthews, B.; Harrod, C.; Stephens, T.; Grey, J.; Markel, R.; Mazumder, A. Lipid extraction has little effect on the $\delta 15 \mathrm{~N}$ of aquatic consumers. Limnology and Oceanography: Methods 2007, 5(10), 338-342.

(36) Kleiber, C.; Zeileis, A. Package 'AER'. R package version 1.2-4, https://cran.rproject.org/web/packages/AER/AER.pdf, 2015

(37) US EPA, EPIWEB 4.11, https://www.epa.gov/tsca-screening-tools/download-epi-suitetmestimation-program-interface-v411, last accessed in June 2019.

(38) Pinheiro, J.; Bates, D.; DebRoy, S.; Heisterkamp, S.; Van Willigen, B. Package“nlme.” Available at https://cran.r-project.org/web/packages/nlme/nlme.pdf. (2016)

(39) Houde, M.; Muir, D. C.; Tomy, G. T.; Whittle, D.M.; Teixeira, C.; Moore S. Bioaccumulation and Trophic Magnification of Short- and Medium-Chain Chlorinated Paraffins in Food Webs from Lake Ontario and Lake Michigan. Environ. Sci. Technol. 2008, 42(10), 3893-9. 
(40) Huang, H.; Gao, L.; Xia, D.; Qiao, L. Bioaccumulation and Biomagnification of Short and Medium Chain Polychlorinated Paraffins in Different Species of Fish from Liaodong Bay, North China. Sci. Rep. 2017, 7, 10749.

(41) Sun, R.; Luo, W.; Tang, B.; Zongrui, L.; Huang, L.; Wang, T.; Mai, B. Short-Chain Chlorinated Paraffins in Marine Organisms from the Pearl River Estuary in South China: Residue Levels and Interspecies Differences. Sci. Total Environ. 2016, 553, 196-203

(42) Livingstone, D. R. Organic xenobiotic metabolism in marine invertebrates. In Advances in comparative and environmental physiology Gilles, R. Ed. Springer, Berlin, Heidelberg 1991; pp. 45-185.

(43) Varanasi, U. Metabolism of polycyclic aromatic hydrocarbons in the aquatic environment. CRC press, 1989.

(44) Net, S.; Sempéré, R.; Delmont, A.; Paluselli, A; Ouddane, B. Occurrence, fate, behavior and ecotoxicological state of phthalates in different environmental matrices. Environ. Sci. Technol. 2015, 49, 4019-4035

(45) Kelly, B. C.; Ikonomou, M. G.; Blair, J. D.; Morin, A. E.; Gobas, F. A. Food web-specific biomagnification of persistent organic pollutants. Science 2007, 317(5835), 236-239.

(46) Kraus, J. M.; Walters, D. M.; Wesner, J. S.; Stricker, C. A.; Schmidt, T. S.; Zuellig, R. E. Metamorphosis alters contaminants and chemical tracers in insects: implications for food webs. Environ. Sci. Technol. 2014, 48(18), 10957-10965.

(47) Kelly, B. C.; Gobas, F. A. An Arctic terrestrial food- chain bioaccumulation model for persistent organic pollutants. Environ. Sci. Technol. 2003, 37: 2966- 2974. 
(48) Vives, I.; Grimalt, J. O.; Ventura, M.; Catalan, J.; Rosseland, B. O. Age dependence of the accumulation of organochlorine pollutants in brown trout (Salmo trutta) from a remote high mountain lake (Redo, Pyrenees). Environ. Pollut. 2005, 133(2), 343-350

(49) Fourgous, C.; Chevreuil, M.; Alliot, F. ; Amilhat, E.; Faliex, E.; Paris-Palacios, S.; Teil, M. J.; Goutte, A. Phthalate metabolites in the European eel (Anguilla anguilla) from Mediterranean coastal lagoons. Sci. Total Environ. 2016, 569-570, 1053-1059

(50) Molbert N, Alliot A, Leroux-Coyau M, Médoc V, Biard C, Meylan S, Jacquin L, Santos R, Goutte A. Potential benefits of acanthocephalan parasites for chub hosts in polluted environments. Environ. Sci. Technol. 2020, 54(9):5540-5549.

(51) Xue, X.; Xue, J.; Liu, W.; Adams, D. H.; Kannan, K. Trophic magnification of parabens and their metabolites in a subtropical marine food web. Environ. Sci. Technol. 2017, 51(2), 780-789.

Acknowledgement - The authors thank the PIREN-Seine research program for financial support and fruitful discussions. 
Figure legends

Figure 1: Relationships between levels of PAH (A), phthalates (B), PAH metabolites (C), phthalate metabolites (D), PAH and their main metabolites (E), phthalates and their main metabolites $(F)$ in ng. $\mathrm{g}^{-1}$ lipid weight and trophic levels in a freshwater food web from the urban Orge River, France. (naphthalene: Nap, acenaphthylene: Acy, acenaphthene: Ace, fluorine: F, phenanthrene: Phe, anthracene: Ant, fluoranthene: Fl, pyrene: Pyr, benzo(a)anthracene: BaA, chrysene: Chr, benzo(b)fluoranthene: $\quad \mathrm{BbF}, \quad$ benzo(k)fluoranthene: $\mathrm{BkF}, \quad$ benzo(a)pyrene: $\mathrm{BaP}$, dibenzo(a,h)anthracene: DahA, benzo(g,h,i)perylene: BghiP, dimethyl phthalate: DMP, diethyl phthalate: DEP, di-n-butyl phthalate: DnBP, di-2-ethylhexyl phthalate: DEHP, 1hydroxyphenanthrene: 1-OH-Phe, 1-hydroxypyrene: 1-OH-Pyr, 6-hydroxychrysene: 6-OH-Chr, mono-iso-butyl phthalate: MiBP, mono-n-butyl phthalate: MnBP, mono-benzyl phthalate: MBzP, mono-2-ethylhexyl phthalate: MEHP, mono-2-ethyl-5-oxohexyl phthalate: MEOHP, mono-2-ethyl5-hydroxyhexyl phthalate: MEHHP).

Figure 2: Relationships between levels of short-chain chlorinated paraffins (A), medium-chain chlorinated paraffins (B) and trophic levels in a freshwater food web from the urban Orge River, France

Figure 3: Relationships between trophic magnification factors (TMF), hydrophobicity $\left(\log K_{\mathrm{OW}}\right)$ and metabolic transformation rate (log $k_{\mathrm{M}}$ ) for PAH (Polycyclic Aromatic Hydrocarbons), phthalates, OCP (organochlorine pesticides), PCB (polychlorinated biphenyls), SCCP and MCCP (short- and medium-chain chlorinated paraffins respectively). 
Figure 1
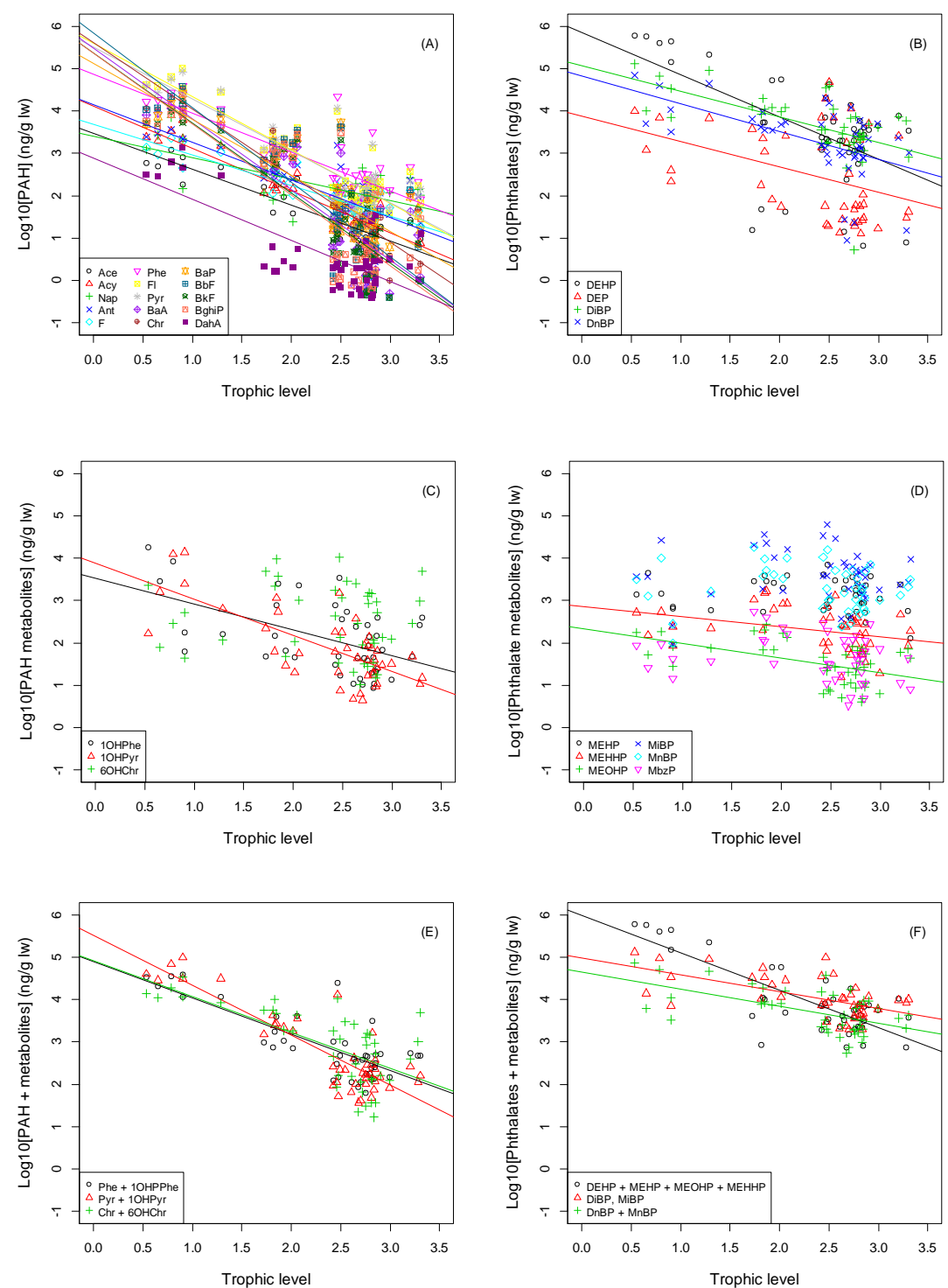
Figure 2
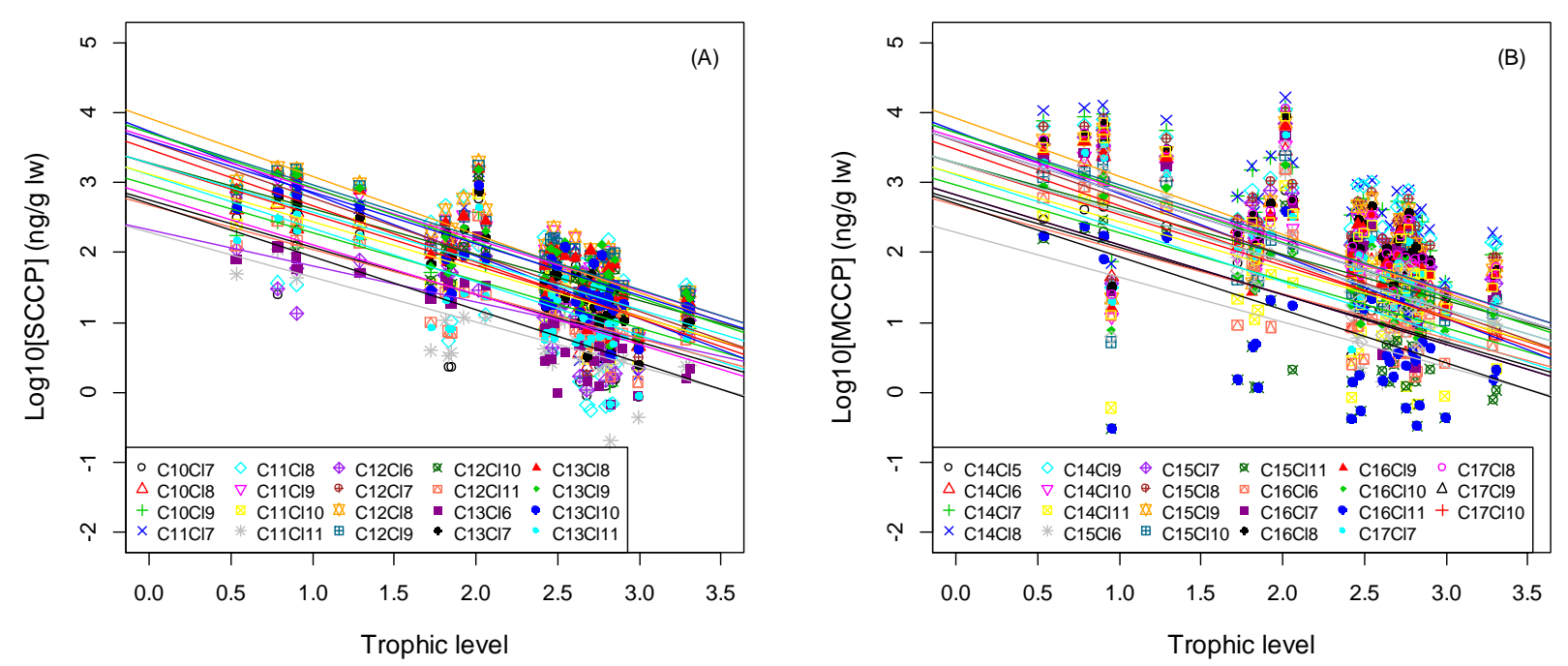
Figure 3
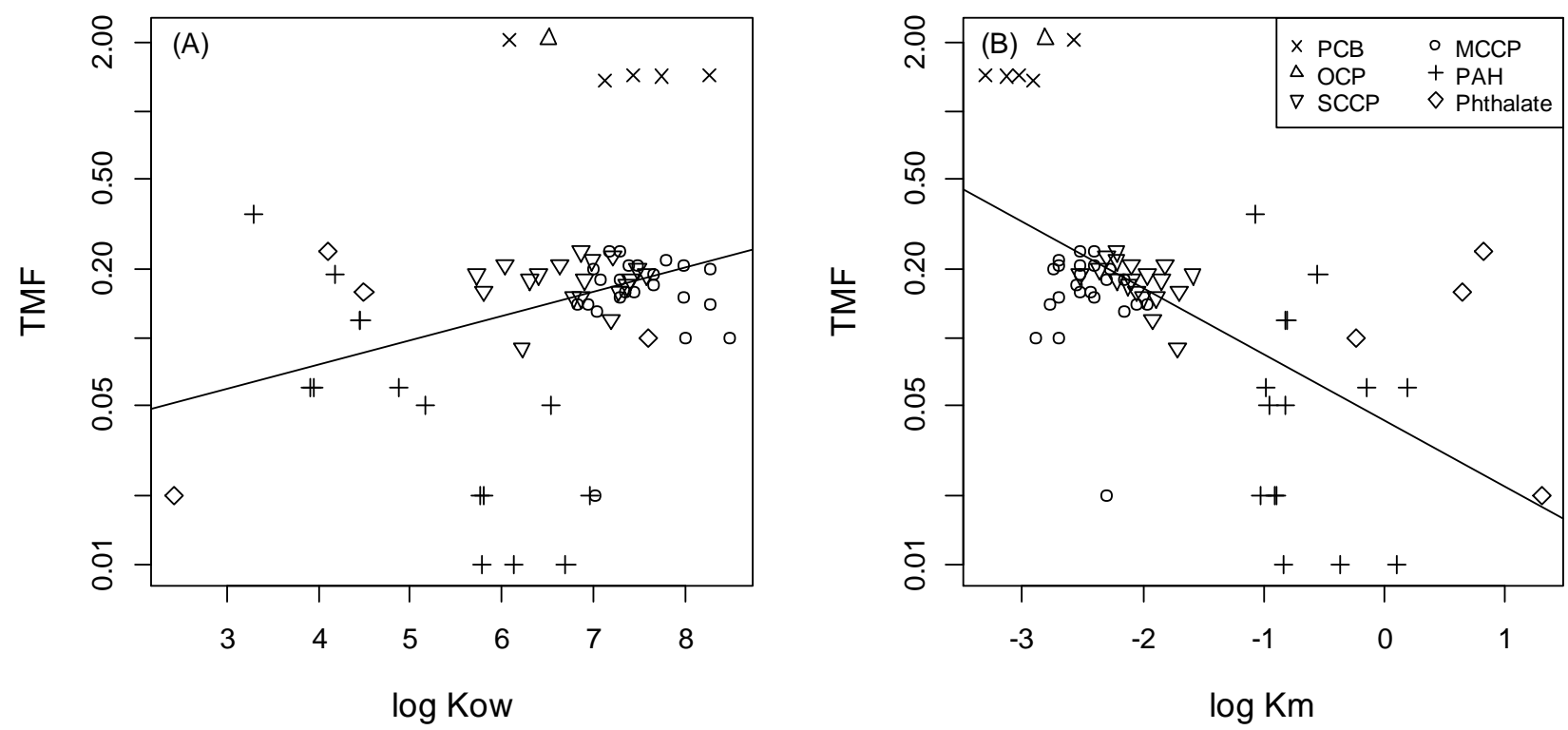